EPJ Web of Conferences 33, 03002 (2012)

DOI: $10.1051 /$ epjconf/20123303002

(C) Owned by the authors, published by EDP Sciences, 2012

\title{
Integrated roof wind energy system
}

\author{
A.B. Suma ${ }^{1, a}$, R.M. Ferraro ${ }^{1}$, B. Dano ${ }^{2}$, and S.P.G. Moonen ${ }^{1}$ \\ ${ }^{1}$ Eindhoven University of Technology, Department of the Built Environment, Vertigo 9.36, Den \\ Dolech 2,5612 AZ Eindhoven, the Netherlands, a.b.suma@tue.nl \\ ${ }^{2}$ University of Miami, College of Engineering, Department of Mechanical and Aerospace \\ Engineering, Coral Gables, FL33146, USA
}

\begin{abstract}
Wind is an attractive renewable source of energy. Recent innovations in research and design have reduced to a few alternatives with limited impact on residential construction. Cost effective solutions have been found at larger scale, but storage and delivery of energy to the actual location it is used, remain a critical issue. The Integrated Roof Wind Energy System is designed to overcome the current issues of urban and larger scale renewable energy system. The system is built up by an axial array of skewed shaped funnels that make use of the Venturi Effect to accelerate the wind flow. This inventive use of shape and geometry leads to a converging air capturing inlet to create high wind mass flow and velocity toward a vertical-axis wind turbine in the top of the roof for generation of a relatively high amount of energy. The methods used in this overview of studies include an array of tools from analytical modelling, PIV wind tunnel testing, and CFD simulation studies. The results define the main design parameters for an efficient system, and show the potential for the generation of high amounts of renewable energy with a novel and effective system suited for the built environment.
\end{abstract}

\section{Introduction}

Awareness and the need for effective renewable energy solutions to be implemented at the location the energy is used, has reached to all parts of society, including governments at the European and National levels, Small and Medium Enterprises (SME) and large industry parties, the scientific community, project developers, building owners, and leasing collectives [1]. The increasing energy demand for industry and households together with rising cost have brought this urgent need to the top of society's critical list in order to keep current living standards affordable, protect and maintain society developments and promise for a healthy future [2]. In 2004, energy consumption by the European industrial, commercial and residential sectors reached up till $71 \%$ of total electricity use. The US Energy Information Administration (EIA) states in its International Energy Outlook 2011 that the global energy consumption will rise with 53\% from 2008 to 2035 . In Europe, residential units consume $29.2 \%$ of total electricity use in the EU-15 and $28.8 \%$ in the contours of EU-27 [3]. To address this current and future need, more effective solutions for harvesting renewable energy sources on the short term are needed.

\footnotetext{
a e-mail : a.b.suma@tue.nl
} 
Available solutions for renewable energy in the built environment are under continuous development to become more efficient and attractive. Some of the negative side effects are: horizon pollution, large required areas with relative high cost and low efficiency (solar) [4], and creation of additional carbon dioxide (biomass). As being the cheapest of the renewable electricity technologies, onshore wind energy will be the largest contributor to meeting the $34 \%$ share of renewable electricity needed for the Union commitment. All EU Members States following the EU Renewable Electricity Directive passed in 2009 are investing in wind power [5]. To give more impulse to renewable energy developments in the built environment, the EU government is preparing regulations to achieve the EU2020 target; pursuing only new construction of 'nearly zero energy' government buildings by 2018 and public buildings by 2020 [6]. Relevant improvement is given by the strong investment not only in the wind energy farms, but also in micro-wind energy, which offers major advantage to harvest energy at the utilizing location and educate the society to the new energy reality.

The currently available wind energy turbines can operate continuously, unattended, and 120,000 hours of active operation can be expected over a design lifetime of 20 years [7]. Micro-generation technologies are estimated to have a high potential for successful employment in the built environment [8]. With respect to wind-based solutions, the existing drawbacks include: limited efficiency (i.e. turbines do not produce energy below $3.6 \mathrm{~m} / \mathrm{s}$ [9]); undesirable location (i.e. offshore solves the issue of wind velocity and horizon pollution at $100 \mathrm{~km}$ remote locations, but requires considerable power distribution infrastructure, and high maintenance and inspection cost [10]); and limited applicability in the built environment (i.e. rooftop windmills have dominant visual impact and maintain wind velocity limitations while being noisy, and also unsafe during storms). Urban wind turbines have low power production due to the turbulent flow around buildings, reduced wind speeds in the built environment, and the limited dimension of the blades; furthermore, those systems have a high effect on the architecture of the structure and the urban area. Therefore, new creative solutions need to be developed, considering higher amount of energy harvested, reduced dimensions and integration with building units.

The subject of this study describes an overview of research and development of a wind energy producing system that is integrated in the roof structure of residential or commercial buildings in order to harvest more energy and be more cost efficient with the aim to meet the missing requirements that renewable energy systems have today. Integration not only allows making each separate function more effective, but in addition introduces new, sometimes more useful, functions [11]. The objective of this study is to visualise and numerically confirm the analytical based design with numerical and wind tunnel experimentation to offer a base of data for continuing research.

\section{Integrated Roof Wind Energy System design}

The design of the Integrated Roof Wind Energy System (IRWES) [12] introduces a novel implementation of the Venturi principle [13] into a residential roof structure or as top-up high-rise roof unit. The incoming wind flow is captured in roof openings before it is led through an array of funnels towards a Vertical Axis Wind Turbine (VAWT) in the top of the roof [Fig. 1]. The inlets have dual-purpose as they serve to capture incoming air flow, and as outlets for the outgoing air flow when the wind comes from opposite direction. As the wind flow enters the funnel with external like conditions, the flow will be three dimensionally skewed during its way towards the VAWT, creating both acceleration and turbulence intensity reduction [14]. Fig. 2 illustrates a concept for a dome shaped roof. This configuration captures unidirectional winds, which enables to be more efficient in the urban environment where changing wind interaction angles occur more often due to the numerous surrounding obstacles. In addition, louvers at the funnel entrances direct the façade interacting wind flow into the funnel system: increasing the capturing area, total mass flow rate, and prevent vertical outflow along the line of the roof. The louvers also take care of adjusting the incoming wind speed or completely seal the entrance during events of extreme weather conditions. The aerodynamic shape of the roof produces a low pressure vertical base flow at the funnel exits at 
the backside of the roof creating a suction effect to enhance the flow exiting from the outlets. The new added function to the roof structure, where the roof becomes a large capturing inlet, generates incremented wind speeds with direct correlation to the amount of energy that can be produced.

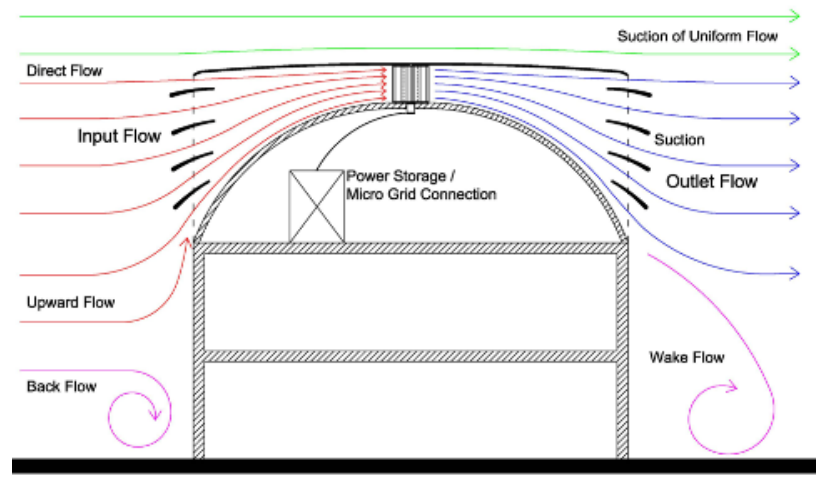

Figure 1: IRWES conceptual design section with flattened dome shaped roof.

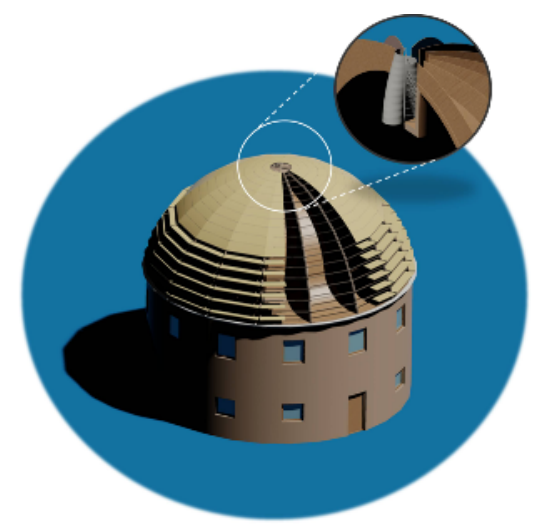

Figure 2: IRWES implemented in a dome roof for unidirectional flow capturing.

\subsection{Vertical axis wind turbine integration}

Conventional VAWT's are usually characterized by a lower efficiency than compared to Horizontal Axis Wind Turbine (HAWT). However, IRWES introduces advantages over conventional VAWT systems and has the potential to meet or exceed the efficiency level of a HAWT:

- Wind capture area for the turbine is formed by the facade of the building from roof top to front facade stagnation point and is substantially larger than a conventionally isolated VAWT;

- Converging inlet guide ducts (funnels) accelerate the flow so that the flow speed striking the turbine is substantially greater than the ambient wind speed, generating a larger blade rotating speed;

- Passages formed by the blades create favourable pressure gradients and hence, significantly larger work output;

- End plates at the turbine entrance will suppress blade tip vortices, and so, generate higher efficiency than conventional VAWT's [15];

- Noise radiation generated by the wind turbine will be significantly lower since the turbine is contained within the roof which will shield the acoustic propagation generated by the blade tip vortices and wakes;

- Dynamic loading generated by the VAWT start-ups will be more efficiently absorbed by the axial arched funnel structure than using a HAWT, introducing a more efficient fatigue design; and,

- vibrations and dynamic loading is isolated from the building's structure by means of rubber blocks.

\subsection{Potential power harvesting estimation}

Preliminary calculations were performed for a case-study design with a dome-shaped roof based on the dimensions of a single-family dwelling derived from Keoleian et al. [16]. The generated power by the building-topped IRWES system can be estimated as:

$$
P=\frac{1}{2} \rho A C_{o p} V^{3} N_{g} N_{b}
$$

where $\mathrm{P}=$ power, $\rho=$ air density, $\mathrm{A}=$ turbine front area exposed to the incoming wind, $\mathrm{C}_{\mathrm{op}}=$ coefficient of performance, $\mathrm{V}=$ wind speed at the turbine inlet, $\mathrm{N}_{\mathrm{g}}=$ generator efficiency, and $\mathrm{N}_{\mathrm{b}}=$ gearbox/bearings efficiency. A conservative estimate for $\mathrm{C}_{\text {op }}$ is 0.35 (Betz limit is 0.59 [17]). The 
generator efficiency varies between $50 \%$ for car alternators up to $80 \%$ or possibly higher for a permanent magnet generator or grid-connected induction generator. The gearbox/bearing efficiency value can reach $95 \%$ in a well-designed system.

From Eq. (1) the power is not only proportional to the turbine front area, but also to the wind velocity cubed. Therefore, the wind acceleration through the inlet guide ducts, due to the reduced area, is highly desirable. Fig. 3 illustrates the estimated power output of an $8 \times 8 \mathrm{~m}$ building. Assuming 50\% of effective wind capture area, and with conservative choice of the other parameters $\left(\mathrm{C}_{\mathrm{op}}=0.35, \mathrm{~N}_{\mathrm{g}}=75 \%, \mathrm{~N}_{\mathrm{b}}=90 \%\right)$, even for moderate wind speeds, the power output can range from 5 to $23 \mathrm{~kW}$. For this dome with an inlet duct area contraction ratio of $1 / 10$, the turbine size would be $1.1 \mathrm{~m}$ in radius and $1.1 \mathrm{~m}$ in height.

To illustrate the impact of the system, an estimating comparison is made for single family houses in both Europe and the Netherlands as exemplary location. Using the JRC European's Status report 2006 [18] and the Dutch Centraal Bureau der Statistiek census data [19] for average annual electric energy consumption for households, these outputs can be put into perspective and may be assumed representative. The average annual electricity consumption is $4,343 \mathrm{kWh}$ for the EU-15 countries [18]; respectively Dutch households use 3,407 kWh per year [19]. Main reason for the Dutch lower electricity consumption is the high portion of natural gas used for heating and cooking. The average annual wind velocity in the Netherlands is $4.59 \mathrm{~m} / \mathrm{s}$ [20], and winds are assumed to be steady for this calculation. Using the above turbine data and an inlet guide duct area contraction ratio, this design would supply a constant power output of $17.8 \mathrm{~kW}$, where A1 is the turbine front area and A0 is the roof wind capture-area. From this calculation, the work output is sufficient to supply 9 houses in Europe and 11 houses in the Netherlands at the upper-end of power consumption. These numbers can be influenced by turbulence and urban obstructions, which may give lower wind speed at the funnel inlet. To illustrate different situations, additional inlet wind velocities are given in Fig. 3 . However, higher inlet wind velocities drastically increase the power output. These estimations are based on direct captured flow, excluding facade interaction captured wind and leeward suction.

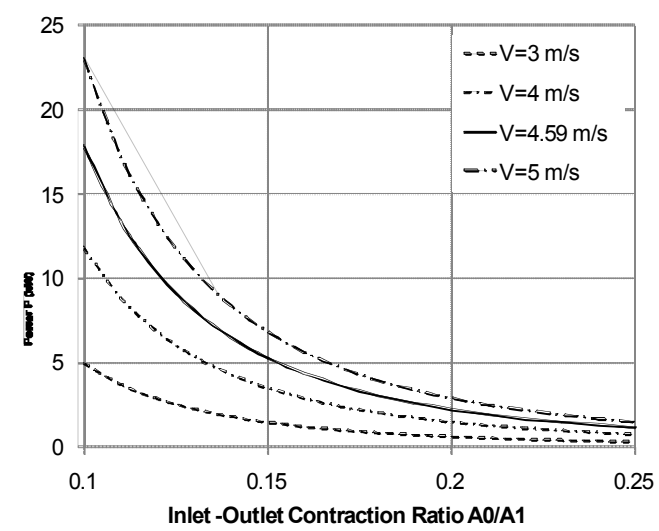

Figure 3: Power estimates by contraction ratios A1/A0, and various wind velocities.

The main design principle of IRWES is based on increased energy harvesting due to the Venturi Effect and placing the turbine where the flow velocity is highest. In larger perspective, the kinetic energy loaded wind volume approaching the building is captured as a large volume and skewed through a single smaller turbine. In direct comparison to free field turbine, it appears highly beneficial to use the building's facade to capture a higher volume of wind for generating energy. Urban windmills are often designed to be placed on roof edges in the shear line of the over-passing wind flow. However, height and location of this shear line depends on wind velocity, wind direction, surface roughness, and obstructions by urban obstacles. IRWES anticipates on this phenomenon by aiming at guiding the shear line into the funnels towards the turbine. 


\section{$2^{\text {nd }}$ European Energy Conference}

\section{Experimental and numerical studies}

Investigations on IRWES performance were first performed using Particle Image Velocimetry (PIV) in a small scale wind tunnel at the University of Miami, Florida, to measure and visualize mass flow through the system. CFD simulations were performed at the Eindhoven University of Technology to carry out a parametric study of main aerodynamic factors influencing the performance of the system. A structural evaluation by means of Finite Element Method (FEM) analysis with different materials and structural setups is ongoing [21] and will be completed with a full scale prototype measurement.

\subsection{Wind tunnel experimentation}

Design optimization is pursued in terms of increasing mass flow in relation to the most effective and aerodynamic shape of the roof and internal system. The challenge is that the total pressure (total energy) of the internal flow after the turbine is lower than the ambient flow due to the turbine work output.

Various non-intrusive techniques, such as laser flow visualization and Digital Particle Image Velocimetry (DPIV) were used to investigate the flow through a scaled model of the VAWT. The wind tunnel cross section is 60 by $60 \mathrm{~cm}$. Using discrete injection of smoke tracers, flow streamlines were visualized to provide qualitative information on the flow behaviour. DPIV consists in seeding the flow uniformly with flow tracers, and imaging series of images with a laser. Post processing of the images provide quantitative velocity information everywhere the tracers are visible. Post processing of the DPIV data provided additional information, such as: vortical structures, airflow instabilities and surrounding disturbances. Results for flow visualization and DPIV are shown in Fig. 4 and 5 , for a wind speed of $5 \mathrm{~m} / \mathrm{s}$. Flow visualization reveals that, with the help of louvers, the building can fully capture the incoming flow by its facade from roof top to front facade stagnation point at $2 / 3$ of total height (Fig. 4a). At the exit, the roof boundary layer is shown turbulent with a coherent vortex structure attached to the trailing edge. The exhaust flow from the turbine exit shows a rapidly dissipating jet (Fig. 4 b).
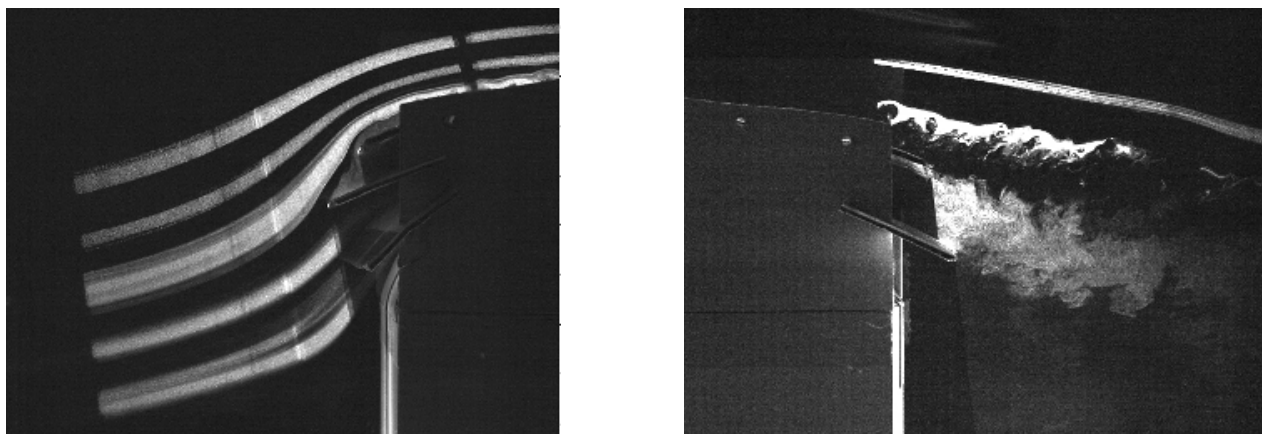

Figure 4: Flow visualization of (a) the windward incoming flow and (b) leeward and exiting flow

Fig. 5 shows an instantaneous PIV measurement of the velocity filed at the exit of the preliminary roof and outlets. By the symmetry of skewed funnels, the velocity has slowed down compared to the inlet velocity illustrating the energy extraction by the turbine. This also promises low noise production at the leeward side of the roof. To achieve the desired wind capturing performance, certain design requirements were found in the experimental exploration studies

1) windward side to capture as much flow as possible;

2) flow over the roof not to be separated; and,

3) external flow on leeward side to create a low pressure base flow region for a suction effect. 


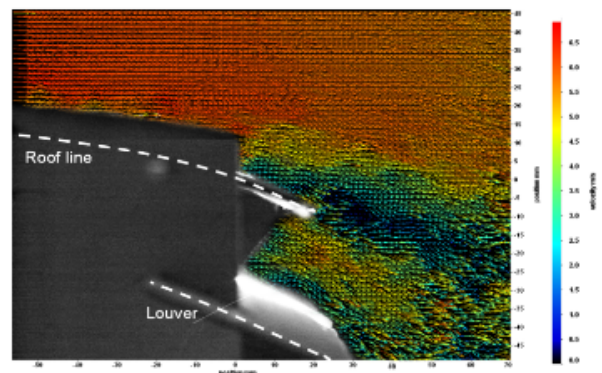

Figure 5: Instantaneous PIV velocity field at the roof exit and top outlet (wind speed $=5 \mathrm{~m} / \mathrm{s}$ )

\subsection{Numerical simulations}

CFD simulation studies have been performed by Ferraro et al. [22] for a flat-shaped roof system of $4 \mathrm{~m}$ high positioned on the top of a rectangular building with dimensions $\mathrm{L} \times \mathrm{B} \times \mathrm{H}(\mathrm{m})=20 \times 20 \times$ 50 [Fig. 6]. A computational reduced-scale model (1:100) has been created to compare simulation results with the data to be obtained from measurements in atmospheric boundary layer wind tunnel.

The two primarily variables analyzed in the parametric study are the number of funnels and louvers [Table 1]. The cross sectional shape of the roof is based on a roof inlet area $A_{0}$ and the turbine inlet area $A_{1}$ creating a contraction ratio of 9 , except in the configuration with zero funnels. The internal roof floor has a curvature based on the polynomial equation used to design wind tunnel ducts. This design is meant to reduce turbulence intensity at the inlet and outlet of the structure. All the simulations were conducted considering an insulated building with no surrounding buildings. In this way, the difference in the flow behaviour detected in the simulation was due only to the configurations implemented by IRWES.

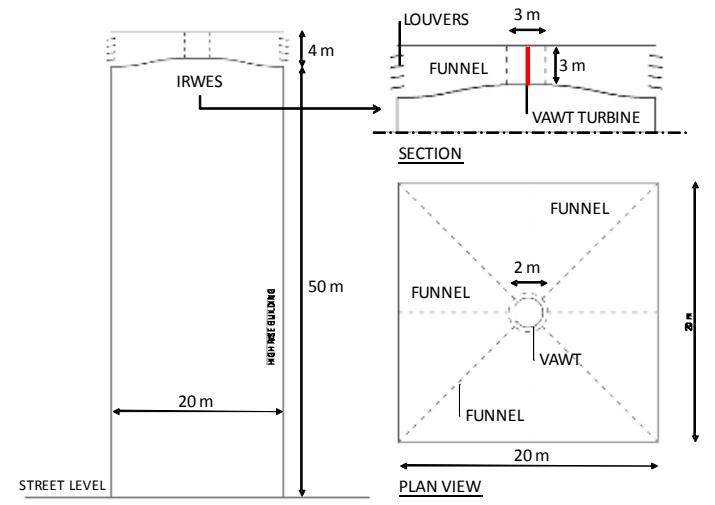

Figure 6: Geometry of the building and of the roof used in the CFD simulation.
Figure 7: Grid generated for configuration IV consisting of $2,861,077$ cells.

Table 1: Roof configurations analyzed

\begin{tabular}{|c|c|c|c|}
\hline Configuration & Nr. of funnels & Setup & Nr. of louvers \\
\hline I & 0 & - & 0 \\
\hline II & 0 & - & 4 \\
\hline III & 4 & Every 90 degrees & 0 \\
\hline IV & 4 & Every 90 degrees & 4 \\
\hline V & 8 & Every 45 degrees & 4 \\
\hline
\end{tabular}

The simulation model was developed using the commercially available general-purpose code FLUENT. The turbulent nature of the flow is modelled by the k-epsilon model. The governing equations are the Navier-Stokes and energy equations which are available in more details in [22]. 
The IRWES' geometry was created using GAMBIT (FLUENT pre-processor). The simulations were evaluated and tested on grid dependency and boundary conditions sensitivity. Fig. 7 illustrates the high quality grid generated for Configuration IV.

CFD simulation studies in the tested geometry indicate that an optimal IRWES configuration contains 4 funnels with each 4 louvers (Configuration IV). Fig. 8 shows that the velocity at the turbine location is as high as the external velocities in the shear line of the building. Furthermore, this configuration showed highest reduction of turbulence intensity and a well distributed wind velocity pattern at the turbine location being most efficient for harvesting highest amount of energy [Fig. 8]. The simulated configuration is not optimal for including facade wind interaction mass flow as tested in the wind tunnel. More optimal geometries may result in a more efficient system.

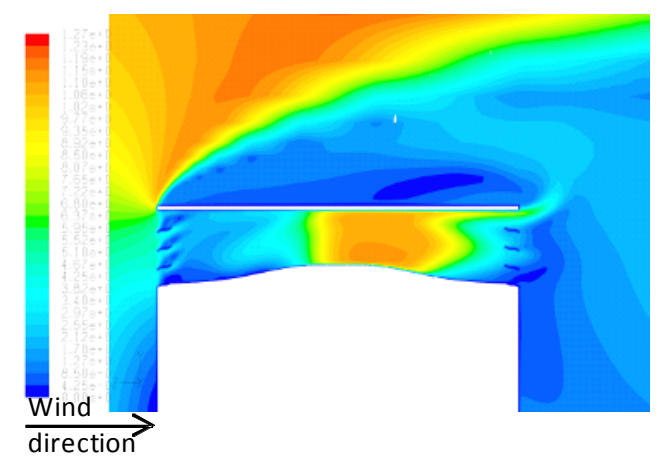

Figure 8: Velocity contours flow analysis of configuration IV.

\section{Conclusion}

The Integrated Roof Wind Energy System is designed to answer to many disadvantages of currently available renewable energy systems. The ability to capture facade interacting wind mass flow, make use of lower wind speeds by accelerating them towards a single turbine, and its architectural integration aspects may combined lead to an effective renewable energy solution for employment in the built environment.

Analytical estimations indicate a potential to harvest a relatively high amount of energy with a single turbine encapsulated in the roof structure. PIV wind tunnel tests confirmed the aerodynamic feasibility of the concept by visualized flow patterns, including capturing of facade interacting flow, and lower pressure suction profile at the leeward side. CFD simulations confirmed the flow accelerations and indicated the most efficient number of funnels and louvers. However, the shape of the simulated model requires improvement to include facade interaction mass flow. Continuation of testing is required to confirm the given energy harvesting potentials.

\section{Future work}

A full scale prototype of $4 \times 4 \mathrm{~m}$ in plan and $6.5 \mathrm{~m}$ height is at final stage of preparation. The building is constructed to be easily modified so that different parameters can be optimized, i.e. contraction ratio. Testing program starts April 1 ${ }^{\text {st }}, 2012$, next to the MAA Airport, Meerssen, the Netherlands.

\section{Acknowledgements}

The authors would like to acknowledge the European Commission and STW for the financial support in the form Marie Curie Fellowship and STW Valorisation Grant Phase I, respectively. The support from the University of Miami, and in particular the Office of Technology Transfer and Department of Civil, Architectural and Environmental Engineering is gratefully acknowledged. 


\section{References}

1. M.A. Brown, and E. Logan (2008) "The Residential Energy and Carbon Footprints of the 100 Largest U.S. Metropolitan Areas," Working Paper \#39, Georgia Institute of Technology

2. O. Dzioubinski, and R. Chipman (1999) "Trends in Consumption and Production: Household Energy Consumption," United Nations Department of Economical and Social Affair Discussion Paper No. 6

3. P. Bertoli, and B. Atanasiu (2007) "Electricity Consumption and Efficiency Trends in the Enlarged European Union," Institute of Environment and Sustainability, Luxemburg

4. A. Goetzberger, C. Hebling, and H.W. Schock (2003) "Photovoltaic Materials, History, Status and Outlook," Materials Science and Engineering, R. 40, pp. 1-46

5. A. Zervos, and C. Kjaer (2009) "Pure Power," A report by the European Wind Energy Association

6. European Commission (2010) “A Strategy for Competitive, Sustainable and Secure Energy," $\operatorname{COM}(2010) 639$, Brussels

7. S.P. Breton, and G. Moe (2009) "Status, Plans and Technologies for Offshore Wind Turbines in Europe and North America," Renewable Energy, Vol. 34, pp. 646-654

8. S. Mertens (2003) "The Energy Yield of Roof Mounted Wind Turbines," Wind Energy, Vol. 27, No. 6, pp. 507-518

9. E. Benini, and A. Toffolo (2002) "Optimal Design of Horizontal-Axis Wind Turbines Using Blade-Element Theory and Evolutionary Computation," Journal of Solar Energy Engineering, ASME, Vol. 124, pp. 357-363

10. C. Hiroux, and M. Saguan (2011) "Large Scale Wind Power in European Electricity Markets: Time for Revisiting Support Schemes and Market Design?,'Energy Policy,Vol.38, pp.3135-3145

11. A.B. Suma, F. van Herwijnen, and J.C.T. Voorthuis (2007) "3D Adaptable Building Skin: Adaptive Space as a Guide Through a Corridor," International Journal of Space Structures, Vol. 22, Nr. 3, pp. 169-177(9)

12. A.B. Suma (2010) "Wind Energy System," U.S. Pat. 20100247302, University of Miami

13. G.B. Venturi (1799) "Experimental Enquiries Concerning the Principle of the Lateral Communication of Motion in Fluids: Applied to Explanation of Various Hydraulic Phenomena," Translated from the French by Nicholson W, 1st English ed., J. Taylor, Architectural Library, High-Holborn, London

14. A. Baylar, M.C. Aydin, M. Unsal, and F. Ozkan (2009) "Numerical Modeling of Venturi Flows for Determining Air Injection Rates Using Fluent 6.2," Mathematical and Computational Applications, Vol. 14, No. 2, pp. 97-108

15. M. Takao, T. Setoguchi, Y. Kinoue, and K. Kaneko (2007) "Wells Turbine with End Plates for Wave Energy Conversion," Ocean Engineering, Vol. 34, Issue 11-12, pp. 1790-1795

16. G.A. Keoleian, S. Blanchard, and P. Reppe (2001) "Life-Cycle Energy, Cost, and Strategies for Improving a Single-Family House," Journal of Industrial Ecology, Vol. 4, Issue. 2, pp. 135-156

17. T. Ackerman (2005) "Wind Power in Power Systems," John Wiley \& Sons, Ltd, Royal Institute of Technology, Stockholm, Sweden, ISBN 0-470-85508-8

18. Jaeger-Waldau Arnulf (2007) "Status Report 2006," JRC Publications Repository, JRC36111, ISBN 978-92-79-05559-1

19. Centraal Bureau der Statistiek (2009) "Use of Electricity, 1995-2008," Compendium voor de Leefomgeving [Dutch]

20. Koninklijke Nederlandse Meteorologisch Instituut (2010), "Klimatologie: Informatie over Het Weer in het Verleden," KNMI, Klimatologie

21. R.W.A. Dekker, R.M. Ferraro, A.B. Suma, and S.P.G. Moonen (2012) "Interdisciplinary Design Study of a High-Rise Integrated Roof Wind Energy System," $2^{\text {nd }}$ European Energy Conference, Maastricht, the Netherlands

22. R.M. Ferraro, A.A. Khayrullina, A.B. Suma, and S.P.G. Moonen (2012) “Aerodynamic study of an Integrated Roof Wind Energy System by means of Computational Fluid Dynamics Simulations," EWEA2012 Annual Event, Copenhagen, Denmark. 